\title{
EDITORIAL
}

\section{Japan's First Open-heart Surgery with Pump Oxygenator}

Yasunaru Kawashima, MD.

Osaka University and National Cardiovascular Center

Fifty years have passed since Japan's first open-heart surgery using a heart-lung apparatus on April 18, 1956 at Osaka University Hospital ${ }^{1}$ - and, in the years since then, the number of open-heart surgeries conducted annually in this country has grown to some 50,000 .

The first patient was a 16-year-old boy with tetralogy of Fallot. Simpler cardiac anomalies such as atrial or ventricular septal defect had been operated upon using hypothermia with or without selective cerebral perfusion before this historic operation, so a tetralogy patient was selected as the first candidate for this procedure as more time was anticipated to be needed.

In this case, however, complete cardiopulmonary bypass time occupied only 14 minutes. Pulmonary valvotomy and closure of the ventricular septal defect were performed through a right ventriculotomy. The patient survived the operation and his preoperative cyanosis disappeared.

The apparatus used for cardiopulmonary bypass combined a Sigmamotor pump and a DeWall-Lillehei bubble oxygenator.

The late Professor Hisao Manabe was 34 years old when he conducted this procedure. He later became a professor of surgery, worked at the National Cardiovascular Center, and served as the president of

From Osaka University and National Cardiovascular Center, Osaka, Japan.

Address for reprints: Yasunaru Kawashima, MD, Honorary President, National Cardiovascular Center, 5-7-1 Fujishiro-dai, Suita, Osaka 565-8565, Japan.

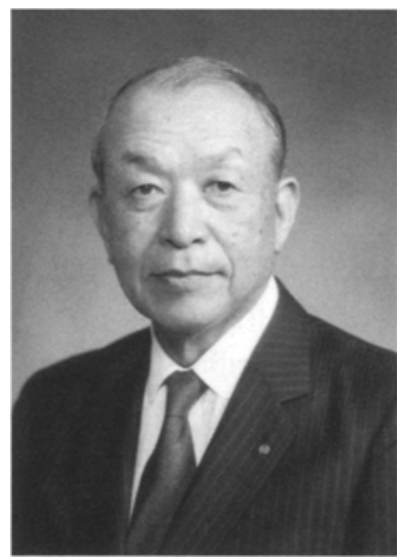

Hisao Manabe, MD.

this institution. This great leader in cardiac surgery in Japan passed away in 1996.

As a successor to this great surgeon, it is my distinct pleasure to be able to have this opportunity to review this dramatic occasion.

\section{REFERENCE}

1. Manabe H, Fujimoto K, Hoshida Y, Sato Y, Morinaga $T$, Kunieda R, et al. Direct vision intracardiac surgery with the aid of heart-lung apparatus. The first successful case in Japan (in Japanese). Rinsho Geka 1956; 11: 443-9. 